\title{
Phase Stability of Ni-base Alloy 625 Produced by Direct Metal Deposition
}

\author{
C. Labre ${ }^{1,2}$, A.L. Pinto ${ }^{1}$ and I.G. Solórzano ${ }^{2}$ \\ 1. Brazilian Center of Research in Physics (CBPF), Rio de Janeiro, Brazil \\ 2. Department of Chemical and Materials Engineering, PUC-Rio, Rio de Janeiro, Brazil
}

Additive manufacturing (AM) technique is based on layer-by-layer growth of solid objects or devices, by fusing consolidating thin layers of loose powder with a scanning laser beam. Among the several existing manufacturing processes, the Direct Metal Deposition (DMD) is an alternative manufacturing route to produce three-dimensional (3D) complex shaped metallic objects. During the construction of a component using DMD, the material is submitted to a thermal cycle which involves abrupt heating over the melting point due the absorption of the laser energy followed by a fast solidification of the melted material. Once the heat source moves, several reheating and cooling occur as a consequence of the following layers deposition and may lead to metastable microstructures [1,2].

Alloy 625, a solid-solution and precipitation-strengthened nickel-base alloy ( $\mathrm{Cr} 24,25 \mathrm{wt} \%$, $\mathrm{Mn}$ 0,38wt\%, C 0,087wt\%, Si 0,52wt\%, Mo 8,96wt\%, Ti 0,0076wt\%, Al 0,0093 wt\%, Nb 3,25wt\%, Fe $2,72 \mathrm{wt} \%$ and $\mathrm{Ni}$ (bal.)), is extensively used in industrial and nuclear energy applications that require a combination of excellent creep and high corrosion resistance at temperatures below $800^{\circ} \mathrm{C}$ [3]. This investigation focused on the microstructural characteristics of two samples of the Inconel 625 alloy produced by DMD. The first sample as-deposited and a second sample aged at $650^{\circ} \mathrm{C}$ during 100 hours after an homogenization treatment at $1200^{\circ} \mathrm{C}$ during 100 hours. Microstructural characterization was performed by SEM (JSM-7100F) and TEM (JEOL 2100F), both equipped with energy dispersive X-ray (EDX) spectrometers. TEM samples from specific areas were prepared by the focused ion beam (FIB) technique using a FIB/SEM (TESCAN LYRA 3).

Figure 1A shows a SEM image as-deposited microstructure was characterized by the presence of a pronounced solidification with columnar dendritic structure, growing epitaxially along the deposition direction. This is the result of a dendritic regions growth under constitutional supercoiling conditions allowing solute partitioning. The sample annealed at $1200^{\circ} \mathrm{C}$ for 100 hours shows no dendrites but a fully equiaxial grain structure. There was, however, no complete dissolution of the Laves phase, as shown in Fig 1B. In Figure 2A, a bright field (BF) TEM image, a Laves and NbC precipitates developed during manufacturing process are shown in the inter-dendritic regions. After homogenization treatment at $1200^{\circ} \mathrm{C}$ followed by aging at $650^{\circ} \mathrm{C}$ during 100 hours occur the precipitation of $\mathrm{M}_{23} \mathrm{C}_{6}$ carbide namely at interface and grain boundaries, as shown in Figure 2B. STEM BF image and corresponding elemental maps extracted from the STEM-EDX spectrum image datasets are shown in Figure 3. The STEM-EDX data from these precipitates revealed that $\mathrm{M}_{23} \mathrm{C}_{6}$ phase is enriched in $\mathrm{Cr}, \mathrm{Ni}$, $\mathrm{Fe}$ and Mo. The stability of other phases, under different aging conditions, is reported elsewhere [4].

References:

[1] Y.J. Zhang et al, Journal of Alloy and Compounds 570 (2013), p. 70.

[2] D. Herzog et al, Acta Materialia 117 (2016), p. 371.

[3] J. Hernandez, L. E. Murr et al, Journal of Materials Science Research 1 (2012), p. 124.

[4] The authors are grateful to CBPF for providing full access to the LABNANO Electron Microcopy facilities and to the Brazilian Funding agencies CNPq, FINEP and FAPERJ. 


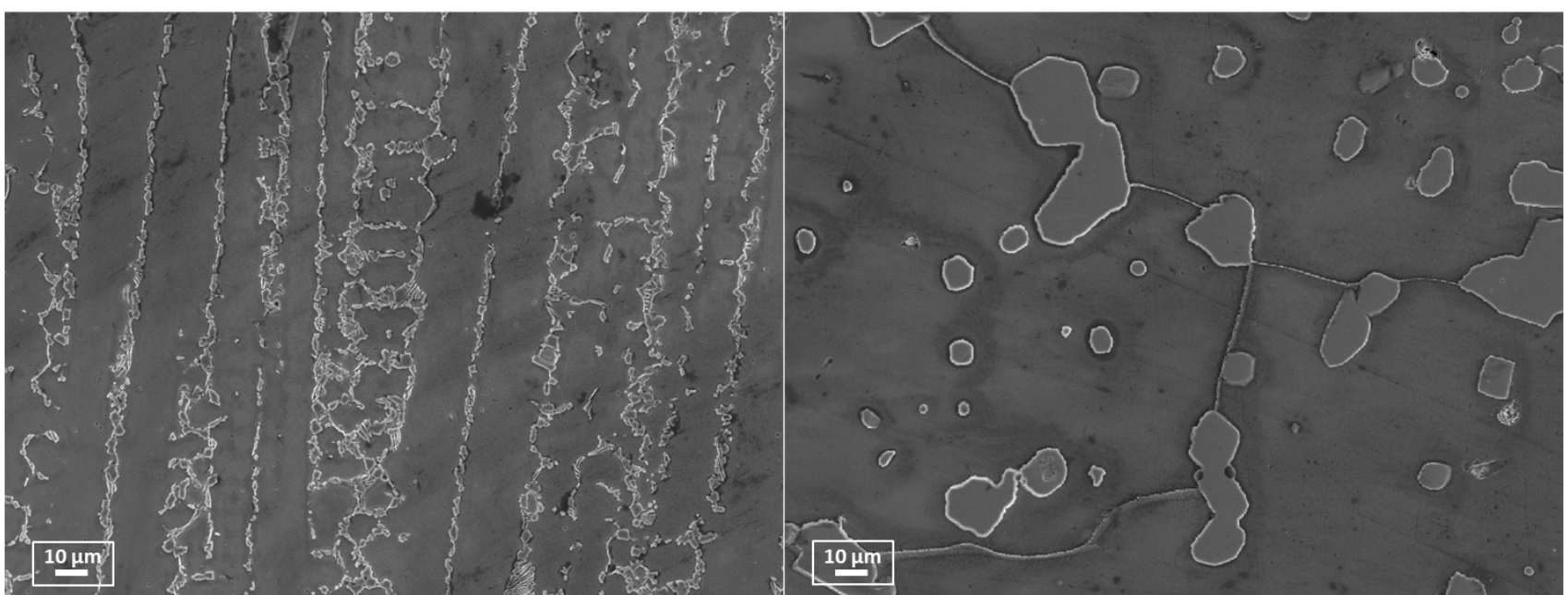

Figure 1. SEM image Alloy 625 sample produced by DMD, showing dendritic solidification microstructure (A) and fully equiaxed grain structure developed after annealing at $1200^{\circ} \mathrm{C}(\mathrm{B})$.

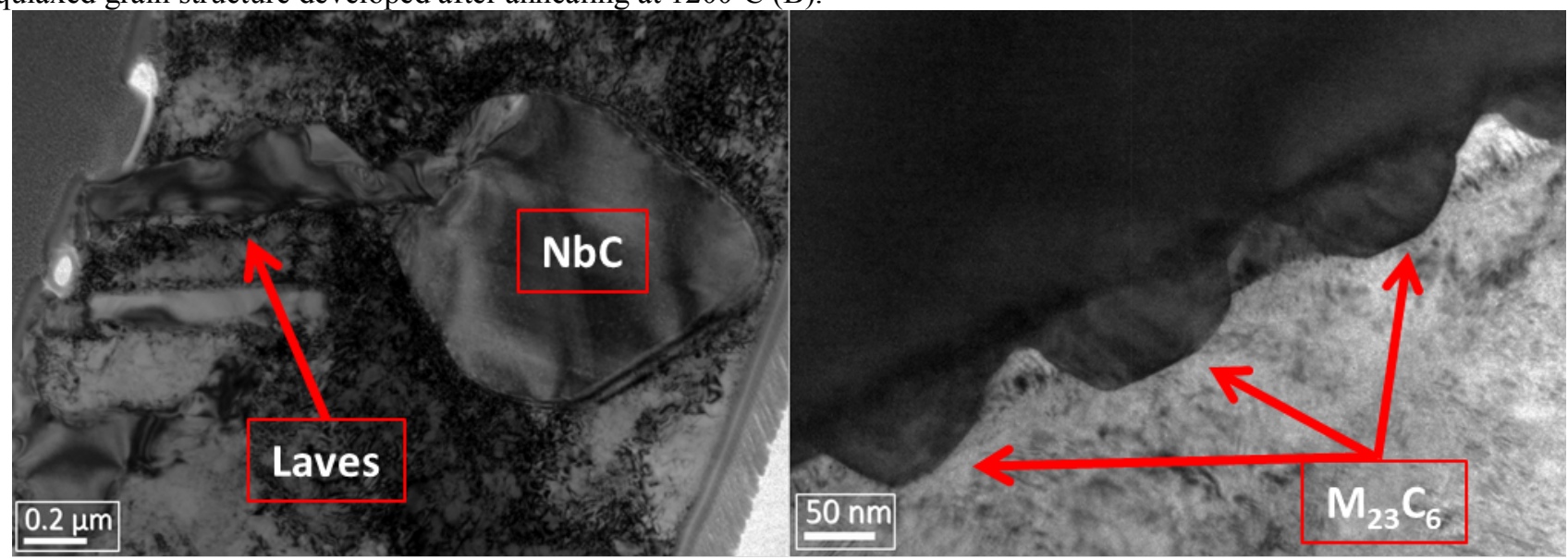

Figure 2. TEM image showing Laves precipitates and $\mathrm{NbC}$ carbides $(\mathrm{A})$ and $\mathrm{M}_{23} \mathrm{C}_{6}$ carbide (B).

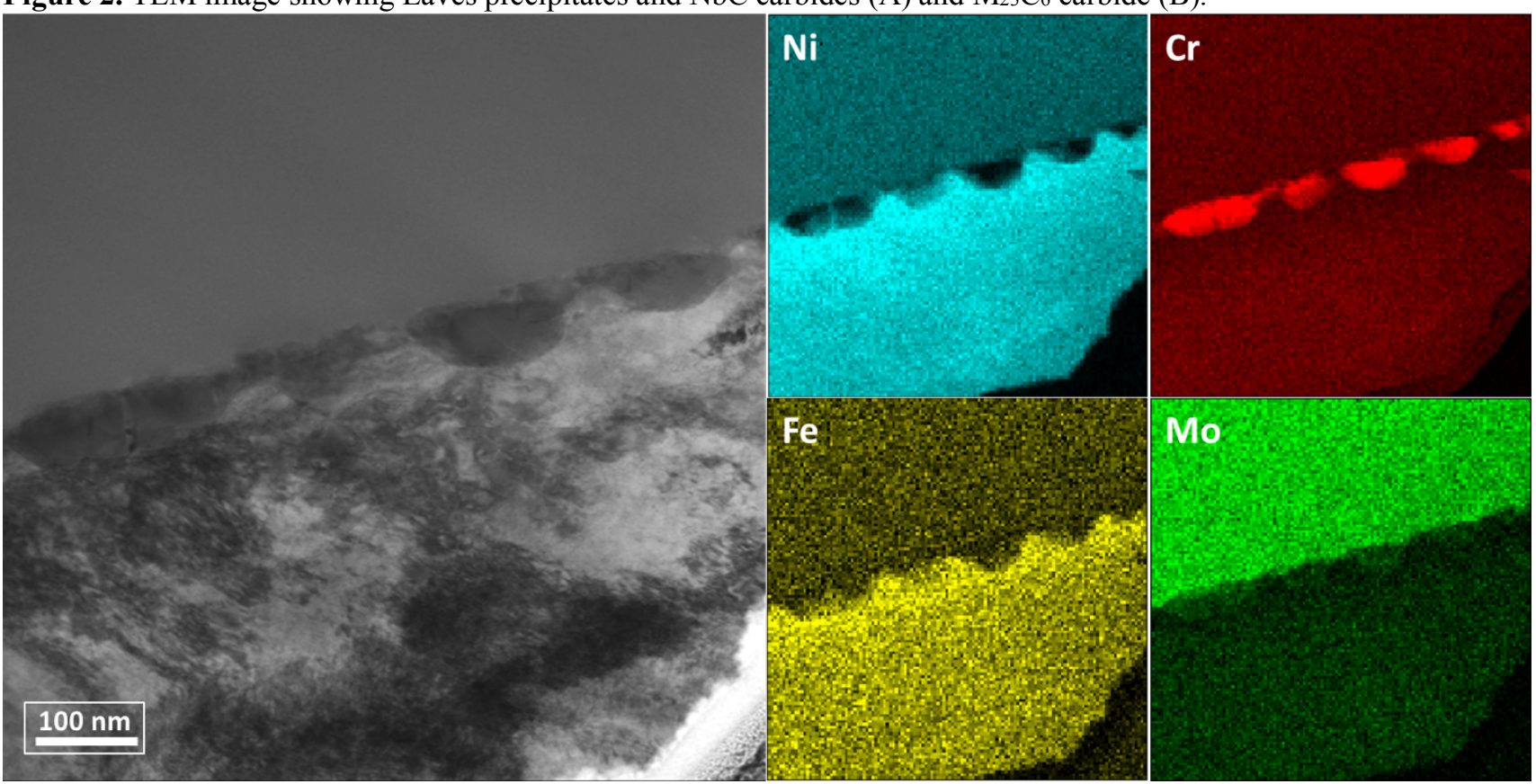

Figure 3. BF TEM image and EDS elemental mapping of $\mathrm{M}_{23} \mathrm{C}_{6}$ grain boundary precipitates containing $\mathrm{Ni}, \mathrm{Cr}$, Mo and $\mathrm{Fe}$. 